\title{
Relationship of ADMA Levels with Cardiovascular Parameters in Patients with Peritoneal Dialysis: A Bioimpedance Analysis Study
}

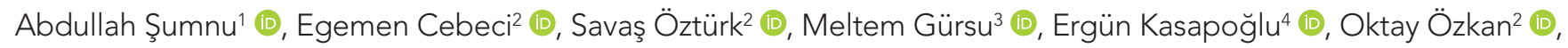

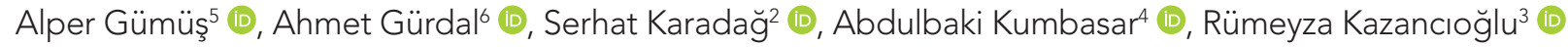 \\ 'Department of Nephrology, İstanbul Medipol University School of Medicine, İstanbul, Turkey \\ 2Department of Nephrology, University of Health Sciences İstanbul Haseki Training and Research Hospital, İstanbul, Turkey \\ ${ }^{3}$ Department of Nephrology, Bezmialem Vakif University School of Medicine, İstanbul, Turkey \\ ${ }^{4}$ Department of Internal Medicine, University of Health Sciences İstanbul Haseki Training and Research Hospital, istanbul, Turkey \\ ${ }^{5}$ Department of Biochemisty, University of Health Sciences Haseki Training and Research Hospital, İstanbul, Turkey \\ ${ }^{6}$ Department of Cardiology, ìstanbul University İstanbul School of Medicine, ìstanbul, Turkey
}

Cite this article as: Şumnu A, Cebeci E, Öztürk S, Gürsu M, Kasapoğlu E, Özkan O, et al. Relationship of ADMA Levels with Cardiovascular Parameters in Patients with Peritoneal Dialysis: A Bioimpedance Analysis Study. JAREM 2018; 8(3): 147-52.

\begin{abstract}
Objective: Asymmetric dimethylarginine (ADMA) is known as a non-traditional risk factor for cardiovascular disease. Considering the increased prevalence of hypervolemia and heart failure in patients with peritoneal dialysis (PD), we aimed to investigate the relationship of ADMA with other biochemical parameters, echocardiographic findings, and results of bioimpedance analysis, which is a method for the determination of body fluid distribution in detail.

Methods: The study was conducted on 21 patients with chronic PD. Bioimpedance was evaluated by Body Composition Monitor H02.201.1®. ADMA level was analyzed by an ELISA kit.

Results: The mean ADMA level was $87.6 \pm 58.2(18.54-247.34) \mu \mathrm{mol} / \mathrm{L}$. The mean ADMA level in patients with hypertension was significantly higher than those with normal blood pressure $(95.8 \pm 58.8 \mu \mathrm{mol} / \mathrm{L}$ and $41.0 \pm 27.9 \mu \mathrm{mol} / \mathrm{L}$, respectively; $\mathrm{P}=0.045)$. In univariate analysis, the parameters associated with serum ADMA levels were uric acid $(r=0.681, p=0.001)$, left ventricular end-systolic diameter (LVESD) ( $r=0.509, p=0.019)$, intracellular water (ICW) $(r=0.606, p=0.004)$, extracellular water $(r=0.471, p=0.031)$, dialysate-to-plasma (D/P) creatinine ratio $(r=0.452, p=0.04)$, body surface area $(r=0.52, p=0.016)$, total body water $(r=0.581, p=0.006)$, and lean tissue mass $(r=0.528, p=0.014)$. In multivariate analysis, only uric acid level, ICW, LVESD, and D/P creatinine were found to be significantly associated with ADMA.

Conclusion: Serum ADMA level may be a useful marker to detect cardiovascular risk in patients with PD. Serum uric acid and LVESD are important parameters related to ADMA levels in patients with PD. Bioimpedance spectroscopy findings support the association of ADMA with body fluid volume.
\end{abstract}

Keywords: Asymmetric dimethylarginine (ADMA), bioimpedance analysis, dialysis, cardiovascular disease, peritoneal dialysis, patients with uremia

ORCID IDs of the authors: A.S. 0000-0003-1185-9737; E.C. 0000-0002-7393-5144; S.Ö. 0000-0002-0961-3810; M.G. 0000-0003-3972-2521; E.K. 0000-00025041-6536; O.Ö. 0000-0003-2061-0124; A.G. 0000-0002-4453-6339; Ahmet G. 0000-0002-2168-4937; S.K. 0000-0001-9535-5063; A.K. 0000-0001-7466-9434; R.K. 0000-0003-1217-588X. 


\section{INTRODUCTION}

Cardiovascular diseases (CVD) are the most important cause of death in patients undergoing dialysis. The traditional risk factors for CVD are also applicable for patients with chronic kidney disease, whereas there are some other factors specific to this population, such as asymmetric dimethylarginine (ADMA) (1).

Endothelial dysfunction (ED) is accepted as the first step in atherogenesis. ED may accompany local depletion of nitric oxide (NO), which is a local vasodilator that also inhibits local platelet adhesion, aggregation, smooth muscle cell proliferation, and interaction of leukocytes with the endothelium. Depletion of NO may be due to decreased endothelial NO production or excessive production of superoxide anions (2).

Asymmetric dimethylarginine shows structural homology to Larginine and inhibits $\mathrm{NO}$ synthase (NOS) and, therefore, might contribute to the initiation and progression of atherogenesis by decreasing the activity of NO (3). Increased ADMA level is associated with ED through inhibition of endothelium-dependent vasodilation $(4,5)$. In recent studies, elevated ADMA level was considered as a predictor of acute cardiovascular events and mortality (6). ADMA infusion reduces blood pressure (BP) and increases systemic vascular resistance in humans (7). ADMA levels increase in the presence of heart failure, coronary artery disease, hypertension, hypercholesterolemia, hyperhomocysteinemia, and diabetes mellitus (8-13). The roles of ADMA in heart failure and endothelial function in heart failure have not been fully elucidated.

Asymmetric dimethylarginine is mainly metabolized by the dimethylarginine dimethylaminohydrolase (DDAH) enzymes in the liver. Approximately one quarter of ADMA is excreted through the kidneys, and ADMA accumulates in the body with decreasing renal function (14). It has also been shown that endothelial function improves with reduced ADMA levels after successful renal transplantation (15). Although ADMA is removed somewhat from the body in patients undergoing dialysis, ADMA levels in patients with peritoneal dialysis (PD) have been found to be significantly higher than those in control subjects (16). Considering the increased prevalence of hypervolemia and heart failure in patients with PD, we aimed to investigate the relationship of ADMA with other biochemical parameters, echocardiographic findings, and results of bioimpedance spectroscopy (BIS), which is a method of determination of body fluid distribution in detail.

\section{METHODS}

All procedures performed in studies involving human participants were in accordance with the ethical standards of the institutional and/or national research committee and with the 1964 Declaration of Helsinki and its later amendments or comparable ethical standards.

Among 69 patients on chronic PD treatment followed up in our PD unit, a total of 21 patients willing to participate and meeting the inclusion criteria were included in the study. Written informed consent was obtained from patients who participated in this study. Exclusion criteria were $<18$ and $>80$ years old, PD duration no longer than 3 months, any advanced valvular heart disease or arrhythmias, any systemic infectious diseases or peritonitis within the last 1 month, malignancy, and class 3 or 4 heart failure according to the New York Heart Association classification.

Primary renal disease, chronic renal failure, and PD duration and medications were recorded in addition to demographic data, such as age, sex, weight, height, and body mass index. BP was measured after at least 10 min of rest in the office. Patients were requested to refrain from tobacco, caffeinated beverages, and alcohol for at least $12 \mathrm{~h}$. BP was measured in both arms supported at heart level in a calm environment with appropriately sized cuff. Korotkoff phase 1 was regarded as the systolic BP, and Korotkoff phase 5 was regarded as the diastolic BP. Mean BP was calculated according to the formula: [(diastolic blood pressure $\times 2)+$ systolic blood pressure]/3.

Echocardiography: A linear probe echocardiograph (Vivid 7, General Electric) was performed in all patients. Measurements of cardiac chambers and ventricular diameters were calculated by using M-mode. Ejection fraction (EF) was calculated by the modified Simpson's rule method. Left ventricular mass (LVM) was calculated by the Devereux formula. LVM index (LVMI) was calculated by dividing LVM by body surface area (BSA). Left ventricular hypertrophy (LVH) was diagnosed if LVMI was $>110 \mathrm{~g} / \mathrm{m}^{2}$ for women and $>134 \mathrm{~g} / \mathrm{m}^{2}$ for men.

BIS: Bioimpedance was evaluated by BCM (Body Composition Monitor H02.201.1®, Fresenius Medical Care, Germany). The device used 50 different frequencies between 5 and $1000 \mathrm{kHz}$ through four electrodes, with two attached to the one upper and two to the lower extremity at the same side. The parameters recorded by this analysis included overhydration, total body water (TBW), extracellular water (ECW), intracellular water (ICW), extracellular/intracellular ratio (E/I), lean tissue mass (LTM), fat ratio, adipose tissue mass, and body cell mass.

Peritoneal equilibration test (PET): PET was performed by filling the peritoneal cavity with $2 \mathrm{~L}$ of dialysis solution containing $2.5 \%$ dextrose or $2.27 \%$ glucose after a routine nocturnal exchange. Urea, creatinine, and glucose levels in the dialysate samples obtained at the beginning, $2 \mathrm{~h}$, and $4 \mathrm{~h}$ were studied together with the same parameters in the plasma samples obtained at $2 \mathrm{~h}$ of PET. Total amount of ultrafiltration at the end of the exchange was recorded. PET results were examined using the Renal Soft ${ }^{\mathrm{TM}}$ version 2.0 Baxter Healthcare, Inc. program.

Blood samples were extracted after a 12-hour fasting for routine hematological and biochemical tests in all patients. Serum glucose, urea, creatinine, uric acid, cholesterol, triglycerides, sodium, potassium, calcium, phosphorus, parathyroid hormone, total protein, albumin, aspartate transaminase, alanine transaminase, total leukocyte count, hemoglobin, hematocrit, ferritin, and highsensitivity C-reactive protein (CRP) levels were studied using appropriate methods. ADMA level was studied by an ELIZA kit (human asymmetrical dimethylarginine, ADMA ELISA Kit, Cusabio Biotech Co., Ltd.) based on competitive enzyme immunoassay method.

\section{Statistical Analysis}

Statistical Packages for Social Sciences 15 (IBM SPSS Corp.; Armonk, NY, USA) software package program for Windows (standard version) was used for statistical analysis. Quantitative 
(numerical) data were expressed as mean \pm standard deviation. For comparison of two groups, paired Student's t-test or MannWhitney $\mathrm{U}$ test (when necessary) was used. For non-numerical

\section{Table 1. Characteristics of the patients}

\begin{tabular}{|c|c|}
\hline Primary kidney disease & $n(\%)$ \\
\hline Diabetic nephropathy & $8(38.1)$ \\
\hline Unknown & $5(23.8)$ \\
\hline Chronic GN & $2(9.5)$ \\
\hline Hypertensive Nephrosclerosis & $2(9.5)$ \\
\hline ADPKD & $2(9.5)$ \\
\hline Chronic PN & $2(9.5)$ \\
\hline Demographic data & Mean (standard deviation) \\
\hline Age (years) & $51.4 \pm(11.9)$ \\
\hline PD duration (months) & $45.0 \pm(25.6)$ \\
\hline $\mathrm{BSA}\left(\mathrm{m}^{2}\right)$ & $1.79 \pm(0.20)$ \\
\hline $\mathrm{BMI}\left(\mathrm{kg} / \mathrm{m}^{2}\right)$ & $28.0 \pm(6.1)$ \\
\hline Biochemistry & Mean (standard deviation) \\
\hline Glucose $(\mathrm{mg} / \mathrm{dL})$ & $153 \pm(94)$ \\
\hline Urea (mg/dL) & $104 \pm(33)$ \\
\hline Creatinine (mg/dL) & $8.0 \pm(2.3)$ \\
\hline Sodium (mmol/L) & $138 \pm(3)$ \\
\hline Potassium (mmol/L) & $4.18 \pm(0.53)$ \\
\hline Calcium (mg/dL) & $9.1 \pm(0.69)$ \\
\hline Phosphorus (mg/dL) & $5.0 \pm(1.0)$ \\
\hline HDL cholesterol (mg/dL) & $45 \pm(17)$ \\
\hline LDL cholesterol (mg/dL) & $118 \pm(36)$ \\
\hline Total cholesterol (mg/dL) & $199 \pm(47)$ \\
\hline Triglyceride (mg/dL) & $182 \pm(93)$ \\
\hline $\operatorname{CaxP}\left({ }^{2} \mathrm{mg} / \mathrm{dL}^{2}\right)$ & $46 \pm(11)$ \\
\hline Albumin (g/dl) & $3.7 \pm(0.4)$ \\
\hline $\mathrm{hs}-\mathrm{CRP}$ (mg/L) & $1.13 \pm(1.49)$ \\
\hline ALT (IU/L) & $16 \pm(8)$ \\
\hline Uric acid (mg/dL) & $6.0 \pm(1.0)$ \\
\hline Transferrin saturation (\%) & $27.7 \pm(9.3)$ \\
\hline Ferritin $(\mathrm{ng} / \mathrm{mL})$ & $301 \pm(189)$ \\
\hline Hematocrit (\%) & $32.4 \pm(3.4)$ \\
\hline Hemoglobin (g/dL) & $10.4 \pm(1.4)$ \\
\hline PTH (pg/mL) & $529 \pm(483)$ \\
\hline ADMA $(\mu \mathrm{mol} / \mathrm{L})$ & $87 \pm(58)$ \\
\hline
\end{tabular}

data, $2 \times 2$ was used for contingency tables; Yates' correction and Fisher's exact test (Fisher's exact) were used where appropriate. Pearson test and Spearman's correlation coefficient were used for analysis of correlation between numerical and non-numerical parameters, respectively. The parameters found to be associated with plasma ADMA levels in univariate analysis were examined by linear regression analysis using the "stepwise" method.

\section{RESULTS}

Of the 21 patients, 13 were female, and 8 were male. The PD modality was continuous ambulatory PD in 12 (57\%), automated PD in 5 (24\%), and continuous cyclic PD in $4(19 \%)$ patients. Of the patients, 18 (85\%) had hypertension, and 9 (42\%) had hyperlipidemia. Table 1 shows the demographic data, primary renal disease, and biochemical data of patients. The most common cause of end-stage renal disease (ESRD) was diabetes mellitus (8 patients, 38\%). Other comorbidities were ischemic heart disease $(n=2)$, congestive heart failure $(n=1)$, and peripheral artery disease $(n=1)$. Of the patients, $5(24 \%)$ were using erythropoiesis-stimulating agent, 9 (43\%) beta-blockers, 11 (52\%) diuretics, 6 (29\%) statins, and 5 (24\%) acetylsalicylic acid. The average amount of urine in 13 patients was $1402 \pm 636 \mathrm{~mL} /$ day, whereas the remaining 8 patients were anuric. The mean systolic and diastolic BPs were $124.5 \pm 36.8 \mathrm{~mm} \mathrm{Hg}$ and $79.8 \pm 11.7 \mathrm{~mm} \mathrm{Hg}$, respectively.

The findings of echocardiographic examination are presented in Table 2. The results of BIS are presented in Table 3. PET findings are presented in Table 4.

The mean ADMA level was $87.6 \pm 58.2(18.54-247.34) \mu \mathrm{mol} / \mathrm{L}$. The mean ADMA level in patients with anuria was higher than those with diuresis, but the difference did not reach statistical significance $(95.5 \pm 59.4 \mu \mathrm{mol} / \mathrm{L}$ vs. $82.7 \pm 59.4 \mu \mathrm{mol} / \mathrm{L}, \mathrm{p}=0.69)$. The mean ADMA level in patients with hypertension was significantly higher than those with normal BP $(95.8 \pm 58.8 \mu \mathrm{mol} / \mathrm{L}$ and $41.0 \pm 27.9 \mathrm{\mu mol} / \mathrm{L}$, respectively; $p=0.045$ )

In univariate analysis, the parameters associated with serum ADMA levels were uric acid $(r=0.681, p=0.001)$, left ventricular end-systolic diameter (LVESD) ( $r=0.509, p=0.019), \mathrm{ICW}(r=0.606$, $p=0.004)$, ECW $(r=0.471, p=0.031), D / P$ creatinine ratio $(r=0.452$, $p=0.04), B S A(r=0.52, p=0.016)$, TBW $(r=0.581, p=0.006)$, and LTM $(r=0.528, p=0.014)$. In multivariate analysis, only uric acid, ICW, LVESD, and D/P creatinine ratio were found to be significantly associated with ADMA (Table 5).

\section{DISCUSSION}

Endothelial dysfunction is the main event in the development of atherosclerosis. NOS inhibition causes CVD via leading ED. Suppressed or decreased activity of NO might contribute to the initiation and progression of atherogenesis through ADMA (3). ADMA has been shown to be related with cardiovascular events and mortality (11). As it is well known, CVD accounts for premature death in $>50 \%$ of patients undergoing dialysis (17). Patients with ESRD have risk factors specific to kidney disease including ADMA in addition to traditional risk factors. In our study, uric acid, LVESD, ICV, ECV, D/P creatinine ratio, BSA, TBW, and LTM were identified as the parameters associated with ADMA. In multivariate analysis, only uric acid, ICV, LVESD, and D/P creatinine ratio were associated with ADMA (Table 5). 
Table 2. Cardiac parameters of the patients

\begin{tabular}{|l|c|}
\hline & $\begin{array}{c}\text { Mean } \pm \text { Std. Deviation } \\
\text { (min-max) }\end{array}$ \\
\hline Aortic diameter $(\mathrm{cm})$ & $3.16 \pm 0.30(2.60-3.60)$ \\
\hline Pulmonary diameter $(\mathrm{cm})$ & $2.15 \pm 0.31(1.70-3.00)$ \\
\hline EF (\%) & $62.5 \pm 8.5(40.0-74.0)$ \\
\hline Deveroux $\left(\mathrm{g} / \mathrm{m}^{2}\right)$ & $266 \pm 84(132-470)$ \\
\hline Deveroux-normalized $\left(\mathrm{g} / \mathrm{m}^{2}\right)$ & $147 \pm 38(93-232)$ \\
\hline LVEDD (cm) & $4.66 \pm 0.46(3.80-5.70)$ \\
\hline LVESD (cm) & $3.04 \pm 0.57(2.30-4.70)$ \\
\hline LVPWD (cm) & $1.18 \pm 0.16(1.00-1.60)$ \\
\hline IVS (cm) & $1.29 \pm 0.25(1.00-2.00)$ \\
\hline LA (cm) & $3.56 \pm 0.59(2.10-4.90)$ \\
\hline RV (cm) & $2.46 \pm 0.19(2.10-2.80)$ \\
\hline $\begin{array}{l}\text { EF: ejection fraction; LVEDD: left ventricular end diastolic diameter; LVESD: } \\
\text { left ventricular end diastolic diameter; LVPW: left ventricular end diastolic } \\
\text { posterior wall dimension; IVS: interventricular septum thickness; LA: left atrium } \\
\text { diameter; RV: right ventricular diameter }\end{array}$ \\
\hline
\end{tabular}

Table 3. Bioimpedance analyses of the patients

\begin{tabular}{|l|c|}
\hline & Mean \pm Std. Dev. \\
\hline Adipose tissue mass (kg) & $37.9 \pm 16.4$ \\
\hline Body Cell Mass (kg) & $18.4 \pm 5.6$ \\
\hline Fat mass (kg) & $27.8 \pm 12.0$ \\
\hline Fat ratio (\%) & $36.2 \pm 11.2$ \\
\hline Extracellular water (L) & $16.8 \pm 3.4$ \\
\hline Intracellular water (L) & $17.4 \pm 3.3$ \\
\hline E/l ratio & $0.97 \pm 0.13$ \\
\hline Lean tissue index (kg/m2) & $12.73 \pm 2.55$ \\
\hline Lean tissue mass (kg) & $33.9 \pm 8.4$ \\
\hline Lean tissue mass ratio & $47.6 \pm 14.6$ \\
\hline Overhydration (L) & $1.87 \pm 2.05$ \\
\hline Total body water (L) & $34.2 \pm 6.2$ \\
\hline E/l ratio: extracellular/intrasellular water ratio & \\
\hline
\end{tabular}

Uric acid is the end product of purine metabolism in humans and is excreted mainly by the kidney. Uric acid level increases in renal failure and is removed from the body by the selected renal replacement modality in ESRD. Epidemiological studies have shown that uric acid was associated with cardiovascular mortality, and this relationship was associated with negative effects on the endothelium $(18,19)$. In a study conducted on non-uremic population in which the effect of uric acid on coronary endothelial function was examined, a significant relationship was found between ADMA and serum uric acid levels in women (20). It has been stated that uric
Table 4. Peritoneal Equilibrium Test (PET) results of the patients

\begin{tabular}{|l|l|c|}
\hline \multicolumn{2}{|l|}{} & Mean \\
\hline $\mathrm{D} / \mathrm{P}$ creatinine & $\left(4^{\text {th }}\right.$ hour) & $0.70 \pm 0.09$ \\
\hline Dialysate & Creatinine clearance (L/week) & $44.7 \pm 10.6$ \\
\hline & Kt/N (weekly) & $1.69 \pm 0.40$ \\
\hline & Urea clearance (L/week) & $60.7 \pm 12.0$ \\
\hline Residual Urine & Amount (mL) & $867 \pm 854$ \\
\hline & Creatinine clearance (L/week) & $31.4 \pm 34.1$ \\
\hline & Kt/N (weekly) & $0.65 \pm 0.70$ \\
\hline & Urea clearance (L/week) & $24.2 \pm 26.3$ \\
\hline Total Kt/N (weekly) & $2.35 \pm 0.68$ \\
\hline D/P creatinine: dialysate/plasma creatinine & \\
\hline
\end{tabular}

Table 5. AMDA-related parameters in multivariate analysis

\begin{tabular}{|l|c|c|c|} 
& $\begin{array}{c}\text { Unstandardized } \\
\text { Coefficients }\end{array}$ & $\begin{array}{c}\text { Standardized } \\
\text { Coefficients }\end{array}$ & Sig. \\
\hline (Constant) & B & Beta & \\
\hline Uric acid (mg/dL) & -388.427 & & 0 \\
\hline LVESD (mm) & 25.27 & 0.464 & 0.001 \\
\hline ICV (L) & 28.718 & 0.281 & 0.026 \\
\hline D/P Creatinine & 6.782 & 0.389 & 0.004 \\
\hline LVESD: left ventricular end systolic diameter; ICV: intracellular volume \\
\hline
\end{tabular}

acid has antioxidant capacity, and increased uric acid levels may play a significant role in increase in vascular oxidative stress (21, 22). In another study including 113 patients with no uremia with chronic heart failure, the ADMA level and uric acid concentration were decreased after administration of allopurinol, and there was an improvement in ED (23). Our study showed that the relationship between ADMA and uric acid was significant in patients with PD similar to those in non-uremic ones. Moreover, this significant relationship may contribute to the increased risk of cardiovascular mortality in patients with PD. ADMA levels have been found to be significantly higher in patients with hypertension PD, and this relationship was thought to be associated with volume overload in patients with PD $(24,25)$. In our study, in which almost all patients were hypertensive, the positive correlation found between ADMA and ICW, ECW, and TBW supports the relationship between ADMA and hypervolemia in patients with PD.

Asymmetric dimethylarginine has the capacity to reduce heart rate and ventricular contraction. The roles of ADMA in cardiac function and endothelial function in heart failure have not been fully elucidated (9). It has been shown that high levels of ADMA had a strong correlation with concentric LVH and carotid artery intima media thickness in addition to increased incidence of car- 
diovascular events (26). Plasma ADMA concentrations in patients with clinically evident atherosclerosis have been found to be higher than those without (27). There was a positive correlation between ADMA levels and left atrial diameter, LVESD, and left ventricular end-diastolic diameter, whereas there was a negative correlation with EF in our study. In addition, the relationship between ADMA and LVESD continued in the multivariate analysis (Table 5). In their study including 131 patients with chronic renal disease, Raconi et al. (28) have stated that ADMA is a strong and independent risk marker for progression to ESRD and mortality. In another study by Mallamaci et al. (29) conducted on 246 patients undergoing dialysis without heart failure, it was reported that ADMA is an important predictor of death and cardiovascular events together with CRP and $\beta$-natriuretic peptide. Li et al. (30) reported that adding nitrates as an antihypertensive to the treatment regimen cause regression of $\mathrm{LVH}$ and lower ADMA levels and independent from BP in patients with PD.

Dialysate-to-plasma creatinine ratio at $4 \mathrm{~h}$ of PET was another independent variable of ADMA levels in our study. To our knowledge, there are no data about this relationship in the current literature. Animal studies have shown that local inhibition of $\mathrm{NO}$ increases intestinal microvascular permeability (31). Therefore, it can be speculated that high levels of ADMA in patients may cause an increase in peritoneal permeability. More detailed studies about this subject are needed. On the other hand, residual renal function may be an important determinant of ADMA level in patients with PD (32). The mean ADMA level in patients with significant urine volume was found to be lower than those without residual renal function, although the difference did not reach statistical significance. The reason for the lack of statistical significance may be the small number of patients in our study.

Our study has some limitations. Relatively low number of patients and cross-sectional nature are the most important issues. However, it is known that patients with PD are relatively small worldwide. Conducting a study among such group of patients, all being analyzed by BIS and echocardiography with such a strict inclusion criterion, may render understandable the small number of patients.

\section{CONCLUSION}

Serum ADMA levels may be a useful biochemical parameter to detect cardiovascular risk in patients with PD. Serum uric acid, $D / P$ creatinine, LVESD, and ICW are important parameters related to ADMA levels in patients with PD. BIS findings support the association of ADMA with body fluid volume.

Ethics Committee Approval: Authors declared that the research was conducted according to the principles of the World Medical Association Declaration of Helsinki "Ethical Principles for Medical Research Involving Human Subjects", (amended in October 2013).

Informed Consent: Written informed consent was obtained from patients who participated in this study.

Peer-review: Externally peer-reviewed.

Author Contributions: Concept - A.S., E.C., S.Ö., M.G., E.K., O.O., A.G., Ahmet G., S.K., A.K., R.K.; Design - A.S., E.C., S.Ö., M.G., E.K., O.O., A.G., Ahmet G., S.K., A.K., R.K.; Supervision - A.S., E.C., S.Ö., M.G., E.K., O.O., A.G., Ahmet G., S.K., A.K., R.K.; Resources - R.K., S.Ö., A.K.; Materials
- R.K., A.G.; Data Collection and/or Processing - A.G., Ahmet G, O.O.; Analysis and/or Interpretation - A.S., E.C.; Literature Search - S.K., R.K.; Writing Manuscript - A.S., E.C., S.Ö. ; Critical Review - M.G., A.S., S.Ö., R.K

Conflict of Interest: The authors have no conflict of interest to declare.

Financial Disclosure: The authors declared that this study has received no financial support.

\section{REFERENCES}

1. Avci E, Coskun S, Cakir E, Kurt Y, Ozgur Akgul E. Relations between concentrations of asymmetric dimethylarginine and neopterin as potential risk factors for cardiovascular diseases in haemodialysistreated patients. Ren Fail 2008; 30: 784-90. [CrossRef]

2. Annuk M, Zilmer M, Fellström B. Endothelium-dependent vasodilation and oxidative stress in chronic renal failure: impact on cardiovascular disease. Kidney Int Suppl 2003; 84: 50-3. [CrossRef]

3. Ito A, Tsao PS, Adimoolam S, Kimoto M, Ogawa T, Cooke JP. Novel mechanism for endothelial dysfunction: Dysregulation of dimethilarginin dimethylaminohydrolase. Circulation 1999; 99: 3092-5. [CrossRef]

4. Yılmaz MI, Sönmez A, Saglam M, Qureshi AR, Carrero JJ, Caglar K, et al. ADMA levels correlate with proteinuria, secondery amyloidosis, and endotheliel dysfunction. J Am Soc Nephrol 2008; 19: 388-95. [CrossRef]

5. Faraci FM, Brian JE, Heistad DD. Response of cerebral blood vessels to an endogenous inhibitor of nitric oxide synthase. Am J Physiol 1995; 269: 1522-7. [CrossRef]

6. Sibal L, Agarwal SC, Home PD, Boger RH. The Role of Asymmetric Dimethylarginine (ADMA) in Endothelial Dysfunction and Cardiovascular Disease. Curr Cardiol Rev 2010; 6: 82-90. [CrossRef]

7. Achan V, Broadhead M, Malaki M, Whitley G, Leiper J, MacAllister R, et al. Asymmetric dimethylarginine causes hypertension and cardiac dysfunction in humans and is actively metabolized by dimethylarginine dimethylaminohydrolase. Arterioscler Thromb Vasc Biol 2003; 23: 1455-9. [CrossRef]

8. Liu X, Hou L, Xu D, Chen A, Yang L, Zhuang Y, et al. Effect of asymmetric dimethylarginine (ADMA) on heart failure development. $\mathrm{Ni}$ tric Oxide 2016; 54: 73-81. [CrossRef]

9. Bae SW, Stühlinger MC, Yoo HS, Yu KH, Park HK, Choi BY, et al. Plasma asymmetric dimethylarginine concentrations in newly diagnosed patients with acute myocardial infarction or unstable angina pectoris during two weeks of medical treatment. Am J Cardiol 2005; 95: 72933. [CrossRef]

10. Matsuoka H, Itoh S, Kimoto M, Kohno K, Tamai O, Wada Y, et al. Asymmetrical dimethylarginine, an endogenous nitric oxide synthase inhibitor, in experimental hypertension. Hypertension 1997; 29: 242-7. [CrossRef]

11. Böger RH, Bode-Böger SM, Szuba A, Tangphao O, Tsao PS, Chan, $J R$, et al. Asymmetric dimethylarginine: a novel risk factor for endothelial dysfunction: Its role in hypercholesterolemia. Circulation 1998; 98: 1842-7. [CrossRef]

12. Stühlinger MC, Oka RK, Graf EE, Schmölzer I, Upson BM, Kapoor O, et al. Endothelial dysfunction induced by hyperhomocyst(e)inemia: role of asymmetric dimethylarginine. Circulation 2003; 108: 933-8. [CrossRef]

13. Sibal L, Agarwal SC, Schwedhelm E, Lüneburg N, Böger RH, Home PD. A study of endothelial function and circulating asymmetric dimethylarginine levels in people with Type 1 diabetes without macrovascular disease or microalbuminuria. Cardiovasc Diabetol 2009; 8 : 27. [CrossRef]

14. Nijveldt RJ, Siroen MPC, Teerlink T, Leeuwen PAM. Elimination of asymmetric dimethylarginine by the kidney and the liver: A link to the development of multiple organ failure? Am Soc Nutr Sci 2004; 42: 2848-52. [CrossRef]

15. Claes KJ, Bammens B, Kuypers DR, Meijers B, Naesens M, Sprangers $B$, et al. Time course of asymmetric dimethylarginine and sym- 
metric dimethylarginine levels after successful renal transplantation. Nephrol Dial Transplant 2014; 29: 1965-72. [CrossRef]

16. Jacobi J, Tsao PS. Asymmetrical dimethylarginine in renal disease: limits of variation or variation limits? A systematic review. Am J Nephrol 2008; 28: 224-37. [CrossRef]

17. Miller LM, Sood MM, Sood AR, Reslerova M, Komenda P, Rigatto C, et al. Cardiovascular disease in end-stage renal disease: the challenge of assessing and managing cardiac disease in dialysis patients. Int Urol Nephrol 2010; 42: 1007-14. [CrossRef]

18. Johnson RJ, Kang DH, Feig D, Kivlighn S, Kanellis J, Watanabe S, et al. Is there a pathogenetic role for uric acid in hypertension and cardiovascular and renal disease? Hypertension 2003; 41: 1183-90. [CrossRef]

19. Zoccali C, Maio R, Mallamaci F, Sesti G, Perticone F. Uric acid and endothelial dysfunction in essential hypertension. J Am Soc Nephrol 2006; 17: 1466-71. [CrossRef]

20. Kuwahata S, Hamasaki S, Ishida S, Kataoka T, Yoshikawa A, Orihara $K$, et al. Effect of uric acid on coronary microvascular endothelial function in women: association with eGFR and ADMA. J Atheroscler Thromb 2010; 17: 259-69. [CrossRef]

21. Nieto FJ, Iribarren C, Gross MD, Comstock GW, Cutler RG. Uric acid and serum antioxidant capacity: a reaction to atherosclerosis? Atherosclerosis 2000; 148: 131-9. [CrossRef]

22. Feig DI, Kang DH, Johnson RJ. Uric acid and cardiovascular risk. N Engl J Med 2008; 359: 1811-21. [CrossRef]

23. von Haehling S, Bode-Böger SM, Martens-Lobenhoffer J, Rauchhaus M, Schefold JC, Genth-Zotz S, et al. Elevated levels of asymmetric dimethylarginine in chronic heart failure: a pathophysiologic link between oxygen radical load and impaired vasodilator capacity and the therapeutic effect of allopurinol. Clin Pharmacol Ther 2010; 88: 506-12. [CrossRef]
24. Perticone F, Sciacqua A, Maio R, Perticone M, Maas R, Boger RH, et al. Asymmetric dimethylarginine, L-arginine, and endothelial dysfunction in essential hypertension. J Am Coll Cardiol 2005; 46: 518-23. [CrossRef]

25. Fleck C, Schweitzer F, Karge E, Busch M, Stein G. Serum concentration of asymmetric (ADMA) and symmetric (SDMA) dimethylarginine in patients with chronic kidney diseases. Clin Chim Acta 2003; 336: 1-12. [CrossRef]

26. Zoccali C, Mallamaci F and Tripepi G. Novel cardiovascular risk factors in end- stage renal disease. J Am Soc Nephrol 2004; 154: 77-80. [CrossRef]

27. Kielstein JT, Böger RH, Bode-Böger SM, Schäffer J, Barbey M, Koch $\mathrm{KM}$, et al. Asymmetric dimethylarginine plasma concentrations differ in patients with end-stage renal disease: Relationship to treatment method and atherosclerotic disease. J Am Soc Nephrol 1999; 10: 594-600.

28. Raconi P, Tripepi G, Malberti F, Testa S, Mallamaci F, Zoccali C. Asymmetrical Dimethylarginine Predicts Progression to Dialysis and Death in Patients with Chronic Kidney Disease: A Competing Risks Modeling Approach. J Am Soc Nephrol 2005; 8: 1-5.

29. Mallamaci F, Tripepi G, Cutrupi S, Malotino LS, Zoccali C. Prognostic value of combined use of biomarkers of inflammation, endothelial dysfunction, and myocardiopathy in patients with ESRD. Kidney Int 2005; 67: 2330-7. [CrossRef]

30. Li H, Wang S. Organic nitrates favor regression of left ventricular hypertrophy in hypertensive patients on chronic peritoneal dialysis. Int J Mol Sci 2013; 14: 1069-79. [CrossRef]

31. Kubes P, Granger DN. Nitric oxide modulates microvascular permeability. Am J Physiol 1992; 262: 611-5. [CrossRef]

32. Ebinç FA, Erten $Y$, Ebinç $H$, Paşaoğlu $H$, Demirtaş $C$, Taçoy $G$, et al. The relationship among asymmetric dimethylarginine (ADMA) levels, residual renal function, and left ventricular hypertrophy in continuous ambulatory peritoneal dialysis patients. Ren Fail 2008; 30: 401-6. [CrossRef] 